\title{
Belén Quejigo
}

(Cuenca, I986) Profesora de Filosofía especializada en pensamiento contemporáneo francés. Además es tutora de Pensamiento antiguo en la Escuela de Filosofía y directora de la sección cultural de la Radio del Círculo de Bellas Artes de Madrid. Regularmente colabora con la prensa cultural en medios como CTXT. Por otro lado, ha entrevistado a grandes artistas de la talla de Lita Cabellut, con la que ha escrito el catálogo de la exposición en París y Hong Kong "The army of poets". También ha entrevistado a otros artistas de renombre como Luis Feito, Santiago Sierra, Elvira Santamaría, Regina José Galindo, Teresa Margolles, Rafael Canogar, Daniel Canogar. 


\section{HOMENAJE A SAFO}

Afrodita no te apagues, te veo con tu luz.

Sacudes, destrozas y huyes...

Estás practicando acaso cómo morir.

Conocer es realmente el éxtasis

Lo que te extirpa de ti.

El alma seca casi como el fuego.

El vacío nunca separa nada.

Nadie puede cambiar si no encuentra su opuesto.

Soy un fragmento de Dios.

El que diga que hay dos será castigado porque

el corazón es un tirano.

y una aureola solar. $\boldsymbol{\Psi}$

Protrepsis, Año 7, Número 14 (mayo - octubre 2018). www.protrepsis.cucsh.udg.mx 
IOI 8

Infinitos soles habitan infinitos mundos

e infinitos seres que habitan esos mundos.

"El azar no existe”, dijiste aquel día junto a la muralla

como dos aves extrañas sobre el dolor,

Como otra mitad mortal.

Infinitas veces nos cruzaremos:

prometo iluminarte cada una de esas veces

en otra plaza,

en otra calle,

en otro lugar,

en otra estrella,

en otro mundo.

No te asustes

sólo estábamos aprendiendo cómo no morir. $\mathbf{P}$ 